\title{
NEW REFINEMENTS OF JENSEN'S INEQUALITY AND ENTROPY UPPER BOUNDS
}

\author{
GUOXIANG LU
}

Abstract. In this paper some new refinements of the discrete Jensen's inequality with variables are presented. The new refinements are better than the inequalities given by Simic(2009), Dragomir(2010) and Ţăpuş, Popescu (2012). As the applications of the refinements, stronger upper bounds for the Shannon's entropy are obtained as well.

Mathematics subject classification (2010): 26B25, 26D15, 94A17.

Keywords and phrases: Jensen's inequality, convex function, bounds, refinements, entropy.

\section{REFERENCES}

[1] T. M. Cover And J. A. Thomas, Elements of Information Theory, (2nd edition), John Wiley and Sons, Inc., New York, 2006.

[2] S. S. DRAGOMIR, A refinement of Jensen's inequality with applications for f-divergence measures, Taiwanese J. Math. 14 (1) 2010, 153-164.

[3] S. S. DRAGOMIR, A new refinement of Jensen's inequality in linear spaces with applications, Math. Comput. Model. 52 (9-10) 2010, 1497-1505.

[4] L. Horváth AND J. PeČARIĆ, A refinement of the discrete Jensen's inequality, Math. Inequal. Appl. 14 (4) $2011,777-791$

[5] L. HORVÁTH, A method to refine the discrete Jensen's inequality for convex and mid-convex functions, Math. Comput. Model. 54 (9) 2011, 2451-2459.

[6] L. HORVÁTH, Weighted form of a recent refinement of the discrete Jensen's inequality, Math. Inequal. Appl. 17 (3) 2014, 947-961.

[7] J. L. W. V. JENSEN, Sur les fonctions convexes et les inégalités entre les valeurs moyennes, Acta Math. 30 (1) 1906, 175-193.

[8] P. G. Popescu and J. L. Diaz-Barrero, Certain inequalities for convex functions, J. Inequal. Pure Appl. Math. 7 (2) 2006, Article 41, 5 pp.

[9] S. Simic, On an upper bound for Jensen's inequality, J. Inequal. Pure Appl. Math. 10 (2) 2009, Article $60,5 \mathrm{pp}$.

[10] S. Simic, Best possible global bounds for Jensen's inequality, Appl. Math. Comput. 215 (6) 2009, 2224-2228.

[11] S. Simic, Jensen's inequality and new entropy bounds, Appl. Math. Lett. 22 (8) 2009, 1262-1265.

[12] N. Ţ̆ ĂPUŞ AND P. G. Popescu, A new entropy upper bound, Appl. Math. Lett. 25 (11) 2012, $1887-$ 1890.

[13] J. PEČARIĆ AND J. PERIĆ, Remarks on the paper "Jensen's inequality and new entropy bounds" of S. Simić, J. Math. Inequal. 4 (6) 2012, 631-636. 